\title{
AÇÕES DE SENSIBILIZAÇÃO NA IMPLEMENTAÇÃO DA COLETA SELETIVA SOLIDÁRIA EM UM CAMPUS UNIVERSITÁRIO
}

\author{
Elaine Nolasco ${ }^{1}$ \\ Filipe Ribeiro de Almeida ${ }^{2}$ \\ Maria Cristina de Oliveira ${ }^{3}$
}

Resumo: O estudo teve como objetivo avaliar se as ações educativas realizadas pelo grupo Recicla FUP da Faculdade UnB Planaltina têm sido exitosas em envolver a comunidade acadêmica no processo de descarte seletivo dos resíduos. A coleta de dados foi realizada através de questionário estruturado. Observou-se que mais de $80,0 \%$ dos entrevistados sabem o que é a coleta seletiva. Os murais e as redes sociais são as formas de comunicação apontadas como as de maior impacto. A falta de motivação pessoal e o desconhecimento sobre como fazer o descarte seletivo foram os fatores negativos. Para maior engajamento da comunidade acadêmica, é fundamental que ações educativas de sensibilização sejam contínuas e permanentes, além da institucionalização do projeto.

Palavras-chave: Resíduos Sólidos; Universidade Sustentável; Educação Ambiental; Coleta Seletiva.

Abstract: The objective of this study was to evaluate whether the educational actions carried out by the Recicla FUP group of Faculty UnB Planaltina have been successful in involving undergraduate students, administrative technicians and professors in the process of selective waste disposal. Data collection was performed through a structured questionnaire. More than $80.0 \%$ of respondents know what selective collection is. Murals and social networks are the most pointed actions for the efficient dissemination of knowledge about selective collection. The impediments to selective disposal were lack of personal motivation and lack of knowledge about how to make selective disposal. For greater engagement of the academic community, it is essential that educational awareness raising activities be continuous and permanent, in addition to the institutionalization of the project on campus.

Keywords: Solid Waste; Sustainable University; Environmental Education; Selective Collection.

${ }^{1}$ Universidade de Brasília. E-mail: enolasco@unb.br, http://lattes.cnpq.br/5078193653345941

2 Universidade de Brasília. E-mail:contatofribeiro@gmail.com, http://lattes.cnpq.br/9345648464732414

3 Universidade de Brasília. Email: mcrisoliveira@unb.br, http://lattes.cnpq.br/1440663772914527 


\section{Introdução}

A gestão de resíduos sólidos é um desafio à medida que a produção de resíduos continua a aumentar mundialmente em conjunto com o crescimento do consumo (KASSAYE, 2018). No Brasil, a temática vem ganhando espaço nas últimas décadas principalmente após a instituição do marco legal da gestão de resíduos, a Lei Federal 12.305/10, que dispõe sobre a Política Nacional de Resíduos Sólidos (PNRS) e dá diretrizes relativas ao gerenciamento dos resíduos gerados e práticas sustentáveis voltadas para a responsabilidade compartilhada entre Estado e cidadão (BRASIL, 2010). Mesmo antes da instituição da referida lei, o Decreto Federal 5.940/2006 já estabelecia a implantação da coleta seletiva solidária nos órgãos da administração pública federal direta e indireta, com destinação da fração reciclável às cooperativas de catadores (BRASIL, 2006).

Além dos marcos legais apresentados, tanto a publicação do relatório de Brundtland (NAÇÕES UNIDAS, 1987), o qual difundiu o conceito de sustentabilidade $\mathrm{e}$, posteriormente, quanto o advento da Conferência das Nações Unidas sobre o Meio Ambiente e o Desenvolvimento (Eco-92), que provocou uma alteração nos padrões de produção em todo o mundo (NAÇÕES UNIDAS, 1992), influenciaram a administração pública federal, que vem tentando inserir critérios de responsabilidade socioambiental nas suas atividades cotidianas.

Outro fato marcante no Brasil foi a promulgação do Decreto 7.746/12, que trouxe diretrizes socioambientais a serem implementadas pelas instituições federais no Brasil, dentre elas, a gestão de resíduos sólidos (BRASIL, 2012). Nesse sentido, as universidades públicas federais, administração indireta do governo federal, não podem ignorar os problemas ambientais causados por suas atividades - entre os quais podem-se citar os resíduos sólidos. Em linha com outros setores, a sustentabilidade das instituições de ensino superior (IES) tornou-se uma preocupação mundial para os formuladores de políticas públicas (ALSHUWAIKHAT; ABUBAKAR, 2008).

De acordo com Kassaye (2018), as universidades têm obrigação ética de agir com responsabilidade em relação ao meio ambiente. Elas devem ser não só líderes no movimento de proteção ambiental, mas também protagonistas na construção de um futuro sustentável, mudando pensamentos ao vincular às disciplinas de conhecimento base a transmissão de novas habilidades.

A partir dos marcos legais e históricos mencionados, desde 2014 a Universidade de Brasília (UnB) vem tentando gradativamente implantar o Projeto de Coleta Seletiva Solidária de Resíduos Sólidos nos seus quatro campi. A coleta seletiva é necessária para que a UnB exerça a sua função cidadã na construção de saberes por meio de ações capazes de responder as várias demandas socioambientais relacionadas à gestão de resíduos sólidos. Dessa forma, a universidade assume um papel de valor na promoção de políticas socioambientais responsáveis e solidárias, de modo a produzir mudanças nas práticas e atitudes da comunidade acadêmica, exercendo a

revista brasileira educação ambiental 
importantíssima função socializadora de preservação ambiental nos diversos eixos que representam a base das atividades da Universidade nos seus quatro campi (ZANETI; SILVA, 2016). Por vezes, o gerenciamento de resíduos sólidos, especialmente a coleta seletiva/reciclagem, é um ponto de partida para as iniciativas sustentáveis nas universidades (PIKE et al. 2003; SIMA; GRIGORESCU; BĂLTEANU, 2019).

Os desafios da gestão de resíduos variam desde a redução na produção de resíduos, separação, mudança de hábitos, até a coleta, transporte, tratamento, reutilização e disposição dos resíduos (UNEP, 2005). Para Gonçalves et al. (2010) a correta separação dos resíduos na fonte geradora é a ação mais eficaz para facilitar todo o processo de gestão. No entanto, para a sua efetividade, o engajamento dos indivíduos da comunidade acadêmica é fundamental.

Velazquez, Munguia e Sanchez (2005) relatam que as IES são frequentemente caracterizadas por extensa burocracia, falta de integração devido à gestão descentralizada, altos níveis de pessoal com uma cadeia de responsabilidades pouco clara, e elevada rotatividade de funcionários e estudantes. Tais problemas contribuem para dificultar a implantação das ações sustentáveis. Em outro sentido, estudos sugerem que uma forte liderança, o apoio dos administradores seniores e a adoção de uma política ambiental clara são componentes críticos de projetos ambientais bem-sucedidos (VELAZQUEZ; MUNGUIA; SANCHEZ, 2005; RICHARDSON, 2007; SIMA; GRIGORESCU; BĂLTEANU, 2019).

Desde 2015, a Faculdade UnB Planaltina (FUP), um dos campi da Universidade de Brasília, tem se estruturado para implantar a coleta seletiva. Dentre as iniciativas está um projeto para a instituição da coleta seletiva solidária na FUP (Recicla FUP - www.reciclafup.com.br), que tem como objetivo sensibilizar a comunidade universitária através de ações educativas que estimulem o gerador de resíduos a separá-los corretamente. Sendo assim, o presente estudo tem como objetivo avaliar se essas ações têm sido exitosas em envolver a comunidade acadêmica no processo de descarte seletivo dos resíduos, as possíveis falhas no processo e proposição de melhorias.

\section{Material e método}

O método do trabalho foi baseado no estudo de caso, realizado a partir da análise exploratória dos dados com a aplicação de um questionário, com abordagem quali-quantitativa.

\section{Área de estudo}

O estudo foi realizado na Universidade de Brasília - Faculdade UnB Planaltina (Figura 1), situada na Região Administrativa de Planaltina, região nordeste do Distrito Federal. A FUP foi criada em 2006 e, atualmente, possui quatro cursos de graduação - Ciências Naturais (noturno e diurno), Gestão 
Ambiental (noturno), Gestão do Agronegócio (diurno) e Educação do Campo; bem como, seis cursos de pós-graduação (Ciências Ambientais; Ciências de Materiais; Gestão Pública; Meio Ambiente e Desenvolvimento Rural; Ensino de Ciências; Gestão e Regulação de Recursos Hídricos - ProfÁgua), atendendo um total de 1.355 discentes. São 110 docentes e 48 técnicos distribuídos nas áreas administrativas e demais serviços, conforme informação do setor de Recursos Humanos do campus em 2018.

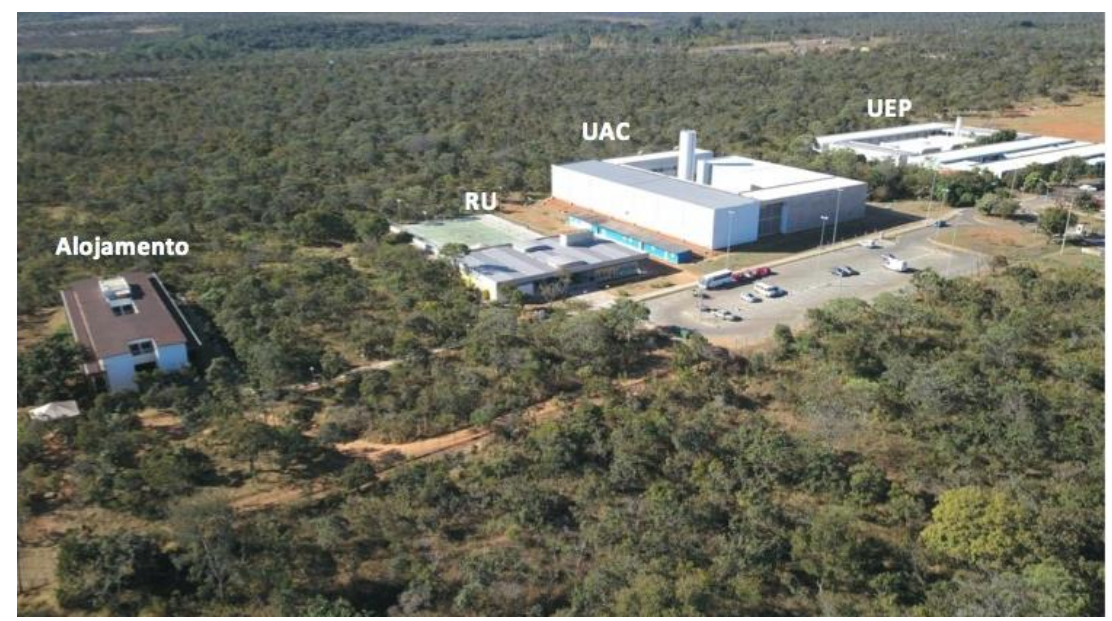

Figura 1: Vista aérea da Faculdade UnB Planaltina (FUP) situada em Planaltina, Distrito Federal, com a distribuição das edificações do campus. UEP: Unidade de Ensino e Pesquisa; UAC: Unidade Acadêmica; RU: Restaurante Universitário e Alojamento.

Fonte: COUTO-JÚNIOR (2017).

\section{Implantação e ações de comunicação e sensibilização}

Em 2015, quando a FUP começou a estruturar o projeto de coleta seletiva, os recipientes foram adquiridos e alguns criados e adaptados para a segregação dos resíduos. Além disso, nesse mesmo ano, por meio de edital público, foi selecionada e contratada uma cooperativa para a coleta da fração reciclável dos resíduos. Assim, em março de 2016, deu-se início à fase de implantação da coleta seletiva e as primeiras ações de sensibilização foram realizadas.

As ações foram iniciadas com reuniões direcionadas aos profissionais de limpeza terceirizados do campus, para treinamento e esclarecimento do novo processo de gerenciamento dos resíduos (Figura 2). Desde então, outras ações educativas e de sensibilização foram realizadas: oficina para produção de lixeiras a partir de latas de tinta (Figura 3); palestras educativas (Figura 4); exposições orais e/ou teatrais com os alunos (Figura 5); produção de materiais informativos como murais, folhetos digitais e faixas educativas e recepção aos "calouros" - alunos recém-admitidos nos cursos - comunicando sobre o projeto de coleta seletiva solidária. Além das ações supracitadas, dois vídeos foram produzidos. O primeiro aborda de forma didática a segregação dos resíduos nos coletores e o acondicionamento temporário destes no campus. $O$ segundo vídeo apresenta o caminho dos resíduos após recolhimento na FUP e o seu processamento na cooperativa de catadores.

revista brasileira educação ambiental 


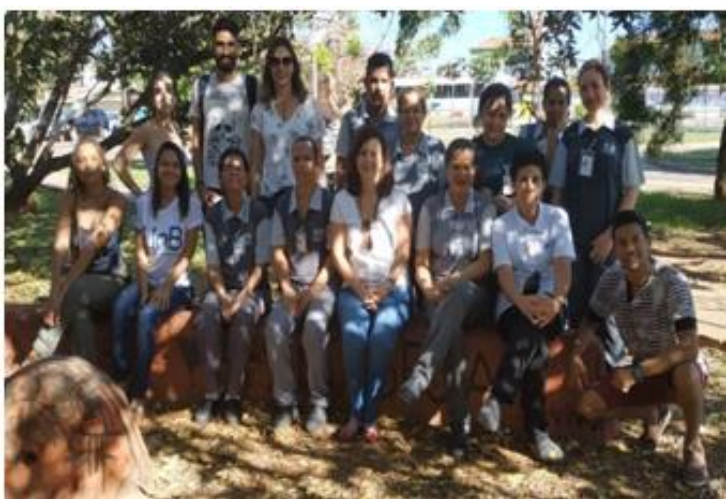

Figura 2: Reunião com a equipe de colaboradores da limpeza do campus. Fonte: autoria própria.

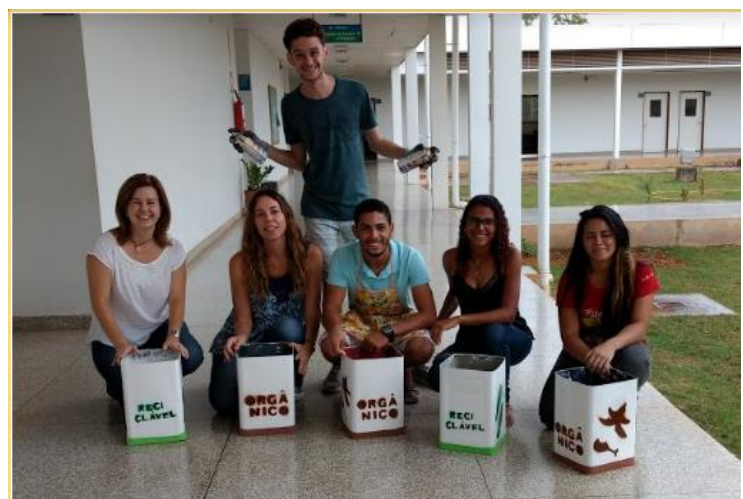

Figura 3: Oficina para produção de lixeiras. Fonte: autoria própria.

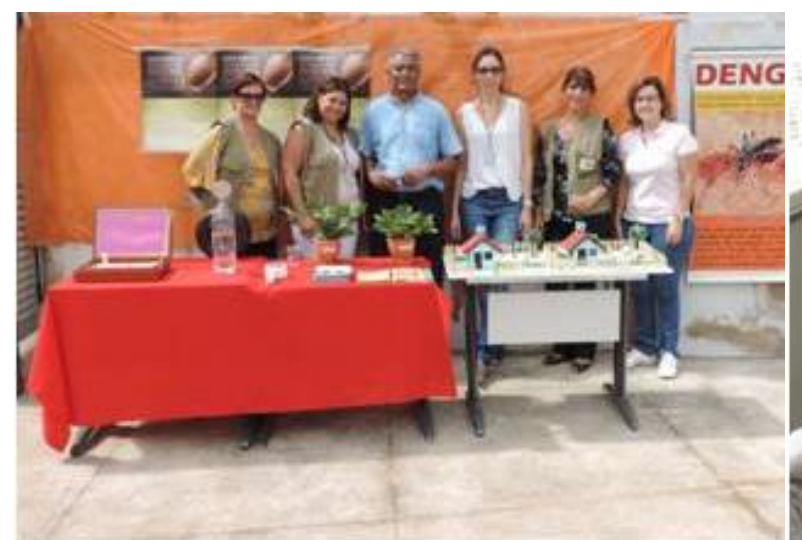

Figura 4: Palestra educativa sobre a dengue. Fonte: autoria própria.

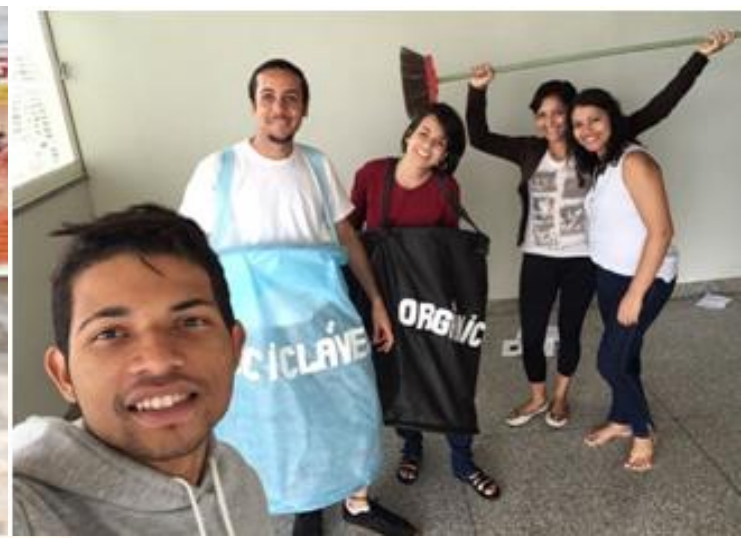

Figura 5: Exposições orais e/ou teatrais com os alunos regulares.

Fonte: autoria própria.

Ademais, em datas comemorativas como: o aniversário da FUP, festas juninas, dia mundial do meio ambiente e natal, são realizadas ações no sentido de mobilizar a comunidade acadêmica para a temática de resíduos sólidos. São destaques: campanha para coleta de resíduos eletrônicos, confecção de ornamentos natalinos utilizando materiais recicláveis, além de ações educativas nas redes sociais.

\section{Coleta de dados}

A coleta de dados foi realizada através de questionário estruturado com seis questões de múltipla escolha. Este foi aplicado aos discentes de todos os cursos de graduação, técnicos administrativos e docentes em outubro de 2018. Para a determinação da representatividade estatística da parcela dos participantes, foi utilizada a seguinte fórmula de Gil (1995): 


$$
n=\frac{\delta^{2} p \cdot q \cdot N}{e^{2}(N-1)+\delta^{2} \cdot p \cdot q} .
$$

Onde: $n$ é o tamanho da amostra, $s^{2}$ é o nível de confiança escolhido, $p$ é a probabilidade de o fenômeno ocorrer, $q$ é a probabilidade complementar, $N$ é o tamanho da população e e representa a probabilidade de ocorrência de erro.

Como os valores de $p$ e $q$ não são conhecidos, atribui-se o valor de 0,5 para as duas variáveis. $O$ tamanho total da amostra é de 1.363 indivíduos. Para atingir um índice de 95\% de confiança, utiliza-se o valor de 1,96 (tabelado). E por fim, utiliza-se o erro de 0,05 (5\%). Assim, obteve-se uma amostra de 262 participantes.

A partir da amostra total, definiu-se o percentual de indivíduos de cada grupo participante (discentes de graduação, docentes e técnicos administrativos) conforme Tabela 1. A seguir, foi realizado o cálculo para que se obtivesse quantos questionários seriam aplicados para cada grupo, sendo esta determinação realizada por meio de análise do percentual que cada grupo representava em relação ao total da população. Para definir quantos questionários seriam aplicados para cada curso de graduação, a mesma metodologia foi utilizada.

As informações obtidas com a aplicação dos questionários foram compiladas em planilhas de dados para fins de análise.

Tabela 1: Distribuição dos grupos entrevistados e seu percentual de representatividade.

\begin{tabular}{lccc}
\hline \multicolumn{1}{c}{ Grupos entrevistados } & Número de Indivíduos & Percentual \% & $\begin{array}{c}\text { N (tamanho da } \\
\text { amostra) }\end{array}$ \\
\hline Discentes de graduação & 1.207 & 88,6 & 232 \\
\hline Docentes & 110 & 8,0 & 21 \\
\hline Técnicos administrativos & 46 & 3,4 & 262 \\
\hline Total & 1.363 & 100 & \\
\hline & Cursos de Graduação & & 59 \\
\hline Gestão do Agronegócio & 305 & 25,2 & 50 \\
\hline Gestão Ambiental & 261 & 21,6 & 43 \\
\hline Ciências Naturais - Diurno & 224 & 18,6 & 40 \\
\hline Ciências Naturais - Noturno & 210 & 17,4 & 40 \\
\hline Educação do Campo & 207 & 17,1 & \\
\hline
\end{tabular}

Fonte: autoria própria. 


\section{Resultados e discussão}

Inicialmente, buscou-se identificar a compreensão dos participantes sobre o que é a coleta seletiva (Figura 6). A média geral indica que $82,5 \%$ dos respondentes sabem o que é o processo de coleta seletiva. Os técnicos administrativos (TA) e os discentes do curso de Educação do Campo (LEDOC) são as categorias com menor conhecimento acerca desse procedimento, pois em média $22,0 \%$ desses respondentes afirmaram que a coleta seletiva é o recolhimento de qualquer tipo de material, o que indica que não possuem fundamentação sobre a prática.

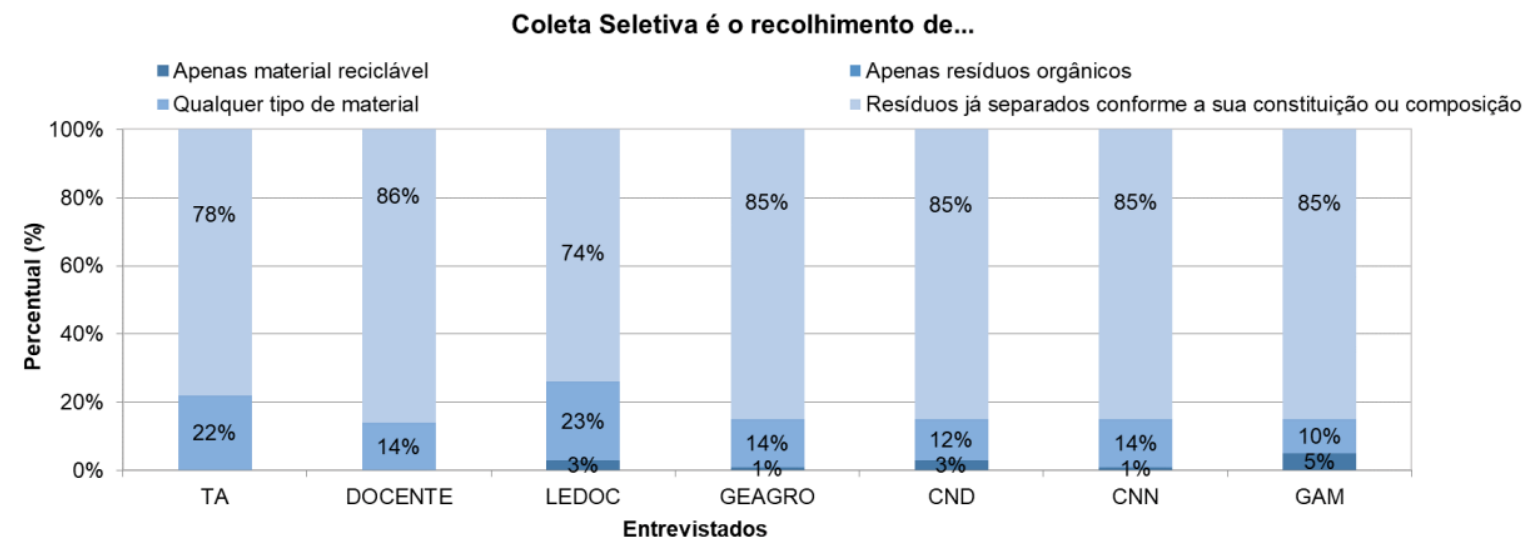

Figura 6: Conhecimento do significado da coleta seletiva. Legenda: TA - Técnico Administrativo; LEDOC - Licenciatura em Educação do Campo; GEAGRO - Gestão do Agronegócio; CND - Ciências Naturais - Diurno; CNN - Ciências Naturais - Noturno; GAM Gestão Ambiental - Noturno. Fonte: autoria própria.

Sobre a existência da coleta seletiva na FUP (Figura 7), em média, $79,6 \%$ dos respondentes afirmaram ter conhecimento de que a referida prática está implantada no campus. Os TAs e docentes foram os grupos mais bem informados, 89,0 e 90,0\%, respectivamente. Por outro lado, os discentes da LEDOC e Gestão do Agronegócio (GEAGRO) apresentaram os menores percentuais, 60,0 e $68,0 \%$, respectivamente. No caso da LEDOC, os discentes possuem frequência acadêmica bimestral e não semestral, funcionando em regime de alternância, o que dificulta o processo de abordagem e sequência do conhecimento. A partir de tais resultados, o que se percebe é que o conhecimento sobre a existência da coleta seletiva na FUP não é homogêneo entre os entrevistados. 


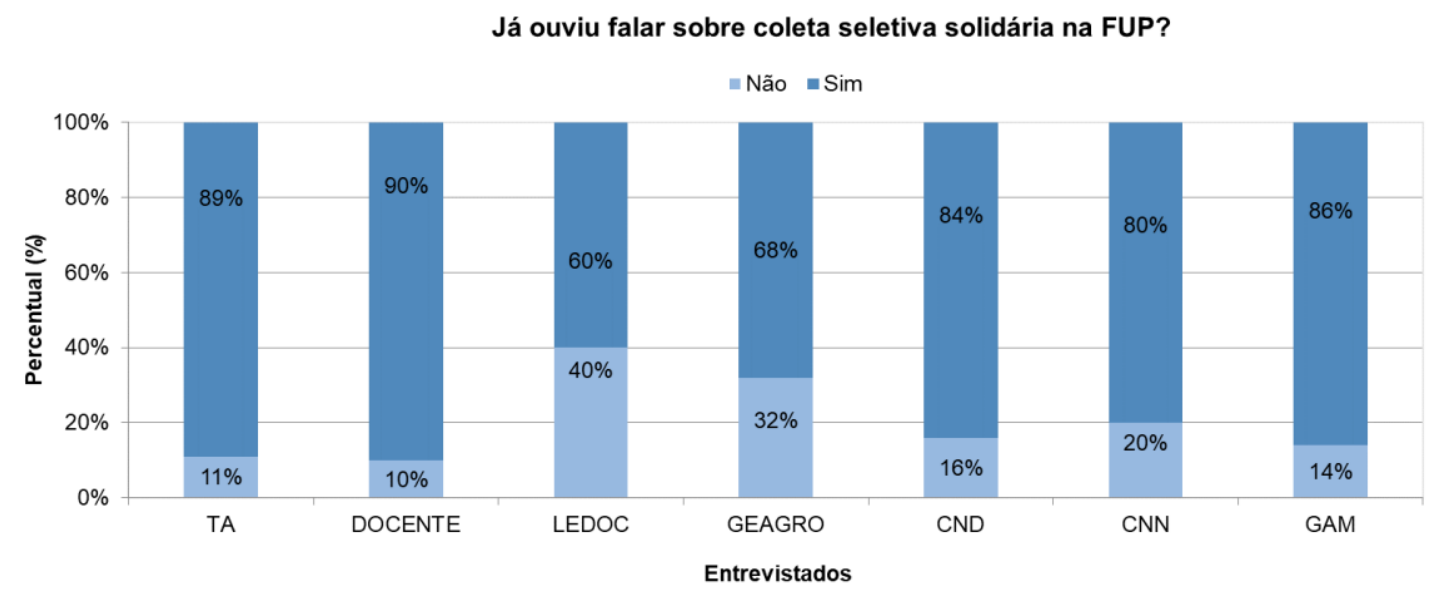

Figura 7: Conhecimento sobre a existência da coleta seletiva na FUP. Legenda: LEDOC Licenciatura em Educação do Campo; GEAGRO - Gestão do Agronegócio Diurno; CND Ciências Naturais - Diurno; CNN - Ciências Naturais - Noturno; GAM - Gestão Ambiental Noturno. Fonte: autoria própria.

Para informar e sensibilizar, diferentes métodos de comunicação foram utilizados a fim de chamar a atenção da comunidade acadêmica quanto aos novos procedimentos adotados no campus (Figura 8). De maneira geral, a maioria (média de 63,1\%) apontou os murais e cartazes como os meios onde viram informações sobre a coleta seletiva no campus. Cárnio et al. (2012) apontaram que grande parte das informações absorvidas pelas pessoas são aquelas advindas do sentido da visão, por isso, faz-se necessária a sensibilização por meio dos estímulos visuais a fim de despertar o interesse e a curiosidade do público.

Conforme os resultados apresentados na Figura 8, em todos os grupos, exceto na LEDOC e Ciências Naturais - Noturno (CNN), a maioria dos respondentes afirmaram ter obtido conhecimento sobre a coleta seletiva em murais e cartazes. Na LEDOC, enquanto $47,0 \%$ afirmaram ser os murais e cartazes os locais onde viram informações sobre a coleta seletiva no campus, outros $40,0 \%$ nunca tinha visto ou ouvido falar dessa questão. Já no grupo das CNN os murais e cartazes $(47,0 \%)$ foram equiparados com aqueles que viram informações em rede sociais $(47,0 \%)$. 


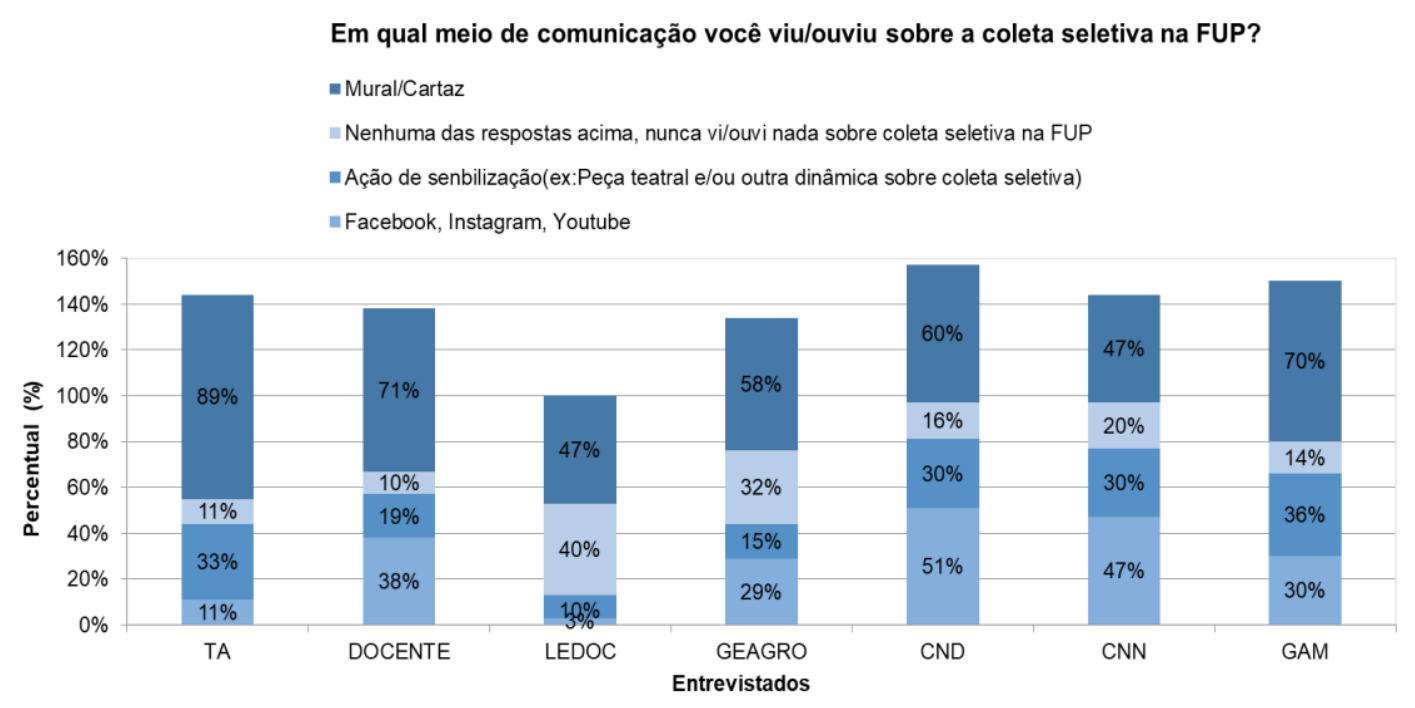

Figura 8: Forma de comunicação pela qual tomou conhecimento sobre a coleta seletiva. Nessa pergunta mais de uma alternativa poderia ser selecionada como correta. Legenda: TA - Técnico Administrativo; LEDOC - Licenciatura em Educação do Campo; GEAGRO - Gestão do Agronegócio - Diurno; CND - Ciências Naturais - Diurno; CNN Ciências Naturais - Noturno; GAM - Gestão Ambiental - Noturno.

Fonte: autoria própria.

O grupo dos docentes, somado aos da CND, apontaram as redes sociais como segundo meio de comunicação onde tiveram conhecimento da coleta seletiva no campus (Figura 8). As ações de sensibilização realizadas de forma presencial foram as abordagens menos indicadas pelos entrevistados, exceto 0 grupo dos TAs, onde 33,0\% admitiu ter conhecido o projeto através desse tipo de abordagem. No grupo da GAM esse tipo de abordagem chamou tanto a atenção $(36,0 \%)$ quanto as redes sociais $(30,0 \%)$. Importante ressaltar que a sensibilização presencial foi o tipo de abordagem menos executada pela equipe do projeto. Por outro lado, $40,0 \%$ dos discentes da LEDOC e $32,0 \%$ da GEAGRO revelaram nunca terem visto ou ouvido falar sobre a coleta seletiva na FUP (Figura 8).

Observou-se que todas as formas de abordagem sensibilizaram um determinado percentual do público alvo, logo, as diversidades de técnicas de sensibilização são importantes nesse processo. Por exemplo, em estudo realizado por Yoshida (2016) na Universidade Tecnológica Federal do Paraná (UTFPR), sobre as estratégias de divulgação da coleta seletiva no campus, foi diagnosticado que dentre as ações de sensibilização realizadas, a gincana solidária cujo objetivo era a construção de ambientes de convivência no campus a partir de materiais recicláveis, com carretéis e pneus, foi considerada a que mais chamou a atenção e então percebida como eficiente pelos alunos. Grønhøj e Thøgersen (2012) sugerem que, para que estudantes ou adolescentes se envolvam mais em iniciativas pró-ambientais, a influência da mídia precisa ser demasiadamente considerada. 
Foi perguntado também aos grupos sobre quais das formas de conscientização tinham chamado mais a atenção (Figura 9). A média das respostas dos grupos elegeram os murais e cartazes $(50,1 \%)$ como a principal. Nesse sentido, o grupo dos TAs é destaque com 78,0\%. Por outro lado, as abordagens indicadas como menos sensibilizadoras foram as dinâmicas presenciais, principalmente entre os alunos do LEDOC e GEAGRO, com 10,0\% e $8,0 \%$, respectivamente.

Em estudo realizado com a comunidade acadêmica da Universidade Federal do Rio Grande do Sul (UFRGS), Samuel e Campani (2009) utilizaram diversas formas de sensibilização visando à separação dos resíduos no campus, a saber: dinâmicas, identificação dos recipientes coletores, cartazes, além de palestras educativas. Após análise, identificaram que a iniciativa com maior êxito foram as palestras educativas sobre a coleta seletiva.

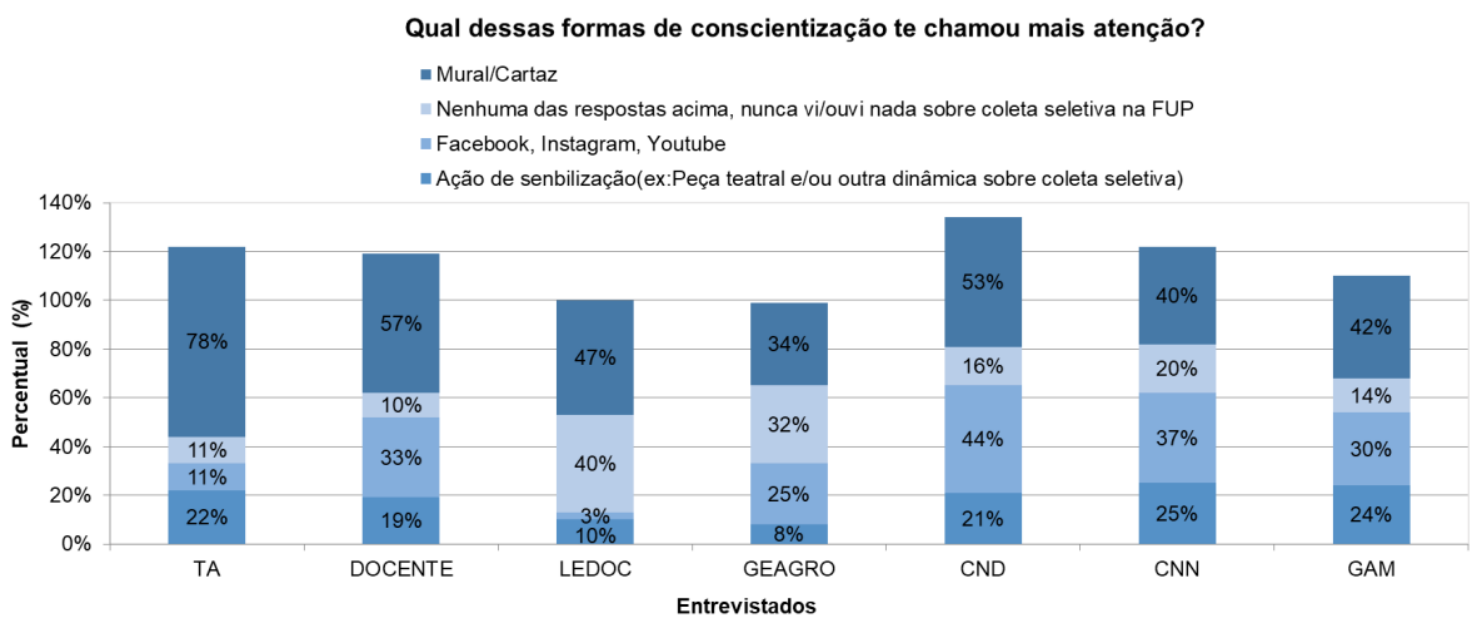

Figura 9: Forma de comunicação que mais sensibilizou o entrevistado. Nessa pergunta mais de uma alternativa poderia ser selecionada como correta. Legenda: TA - Técnico Administrativo; LEDOC - Licenciatura em Educação do Campo; GEAGRO - Gestão do Agronegócio Diurno; CND - Ciências Naturais - Diurno; CNN - Ciências Naturais - Noturno; GAM - Gestão Ambiental - Noturno. Fonte: autoria própria.

No campus da FUP, palestras educativas sobre a coleta seletiva, além de dinâmicas, são ministradas no início do semestre para os calouros. Essa atividade é realizada pela equipe do projeto com apoio institucional. Reconhece-se que a coleta seletiva de resíduos não está no topo da agenda de um aluno quando eles chegam à universidade, portanto as mensagens precisam ser repetidas com bastante frequência (ZHANG et al. 2011). Logo, apesar desta iniciativa ser inovadora em introduzir a questão do descarte seletivo dos resíduos na primeira semana de aula, reforços precisam ser realizados ao longo da vida acadêmica dos alunos no campus.

Em média, 70,0\% dos entrevistados responderam que as ações de sensibilização os ajudaram a realizar o descarte seletivo dos resíduos (Figura 10). Os grupos TA e GAM são os mais mobilizados, com $78,0 \%$ e $76,0 \%$, 
respectivamente. Por outro lado, 25,0\% dos discentes da LEDOC e GEAGRO não mudaram o seu comportamento em função das ações do projeto. De acordo com os resultados apresentados nas Figuras 3 e 4, esses dois grupos foram os menos sensibilizados pelas ações do projeto. Logo, era de se esperar que estes tivessem menor adesão à prática da coleta seletiva no campus. Assim, deve-se pensar em outras técnicas de abordagem/sensibilização para alcançá-los, pois as que são atualmente realizadas não têm se mostrado eficientes para esses grupos.

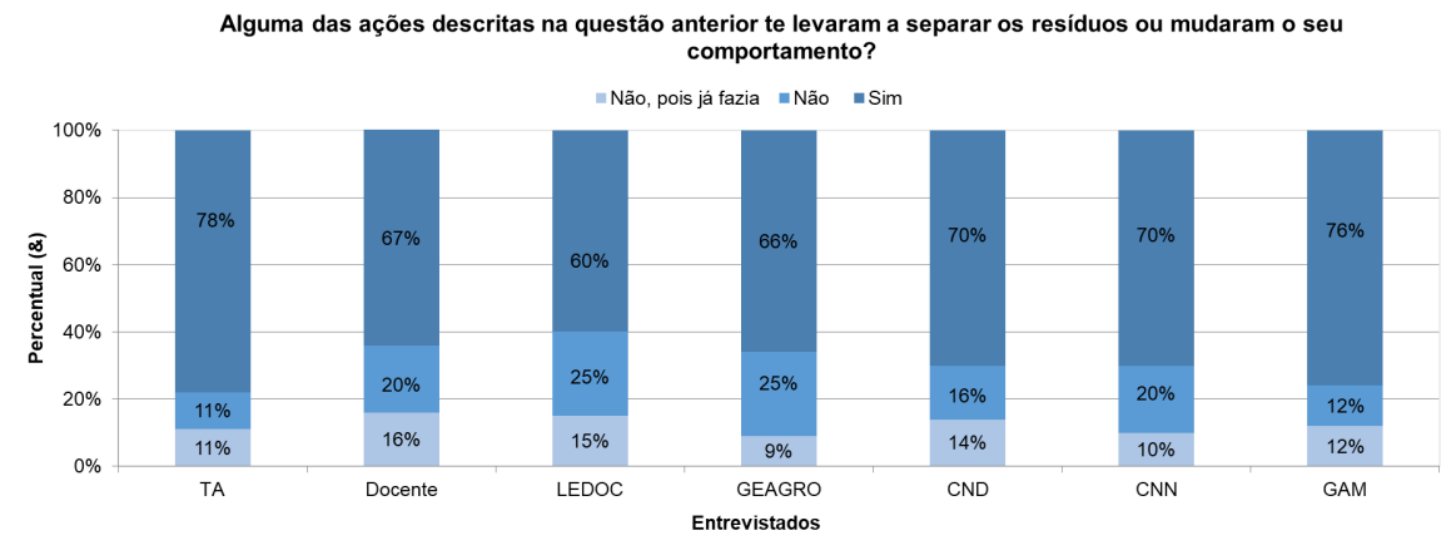

Figura 10: Mudança de comportamento do entrevistado a partir das ações de sensibilização realizadas. Legenda: TA - Técnico Administrativo; LEDOC - Licenciatura em Educação do Campo; GEAGRO - Gestão do Agronegócio Diurno; CND - Ciências Naturais Diurno; CNN - Ciências Naturais - Noturno; GAM - Gestão Ambiental - Noturno.

Fonte: autoria própria.

Um estudo conduzido por Tangwanichagapong et al. (2017), no Instituto Asiático de Tecnologia na Tailândia, identificou que os indivíduos não atingidos pelas campanhas de sensibilização para a separação seletiva dos resíduos sólidos tinham menor preocupação com a temática. Ou seja, quem é sensibilizado através das campanhas educativas tende a ter maior preocupação com o descarte seletivo dos resíduos, pois percebe a importância da prática em um contexto ambiental mais amplo. No caso da FUP, essa afirmativa pode ser comprovada pelas respostas obtidas nas questões 4 e 5 . Ainda de acordo com o estudo supracitado, os entrevistados afirmaram que a realização das campanhas sobre o descarte de resíduos provocou mudança no seu comportamento.

Dentre os cursos, os discentes da GAM foram os mais comprometidos e modificaram o seu comportamento em função das ações de sensibilização. Sabe-se que sentimentos de responsabilidade dos indivíduos são moldados por valores e atitudes (KOLMUSS; AGYEMAN, 2002), dando prioridade àquilo que é considerado de sua responsabilidade. Dessa maneira, quando comportamentos pró-ambientais estão alinhados com as prioridades pessoais, a motivação para fazê-los aumenta. Por outro lado, se contradizem as prioridades, é menos provável que as ações sejam tomadas. Na FUP, o curso 
da GAM tem como objetivo formar profissionais com ampla visão interdisciplinar e sólida base científica do saber ambiental, além de promover o uso sustentável e equitativo dos recursos naturais, assim como contribuir com a internalização da dimensão ambiental nas instituições. Sendo assim, talvez esse seja o maior motivo da participação dos discentes no processo da coleta seletiva - 0 alinhamento das prioridades pessoais com a motivação para 0 comportamento pró-ambiental.

Robinson e Read (2005), afirmam que a diferença entre recicladores e não-recicladores - quem pratica ou não a coleta seletiva - pode ser atribuída à falta de entendimento sobre os programas de reciclagem. Já Vencatasawmy, Ohman e Brännström (2000) encontraram ligações entre grupos demográficos e propensão a reciclar, por exemplo, a aptidão a reciclar os resíduos aumenta $\mathrm{com}$ a idade. $\mathrm{Na}$ amostra estudada pelos referidos autores, a maioria dos participantes eram mais velhos, do sexo masculino, universitários, empregados em período integral. No caso da FUP, a coleta seletiva é mais bem compreendida pelos professores e TAs (Figuras 2 e 5) que, em geral, possuem maior idade e nível de instrução em relação aos estudantes - percebem mais a existência da coleta seletiva no campus e foram alcançados pelas ações de sensibilização realizadas. Esses fatores sozinhos já podem influenciar nas atitudes desses indivíduos em relação à coleta seletiva, tendo em vista que o maior nível de instrução e a maior idade levam a outras oportunidades de aprendizado e experiências, ainda não vivenciadas pela maioria dos jovens estudantes.

Para Zhang et al. (2011), as atitudes dos participantes em relação às ações sustentáveis, em geral, refletem quatro componentes distintos relacionados ao comportamento ambiental e fatores situacionais: a percepção do indivíduo sobre a pressão social ou institucional para reciclar e minimizar a produção de resíduos no trabalho; as consequências do comportamento próreciclagem; fatores situacionais que podem facilitar ou inibir o comportamento para reciclagem; e o controle comportamental percebido pelo indivíduo. Segundo Kollmuss e Agyeman (2002), inúmeros quadros teóricos foram desenvolvidos para explicar a lacuna entre possuir conhecimento e consciência ambiental e a exibição de comportamentos pró-ambientais. Embora muitos estudos tenham sido realizados, nenhuma resposta definitiva foi encontrada. Para Cho (2019), fatores psicológicos determinam a intenção e o comportamento real dos estudantes universitários em participar da reciclagem de resíduos.

Finalmente, na Figura 11, são mostradas as dificuldades enfrentadas quanto à prática da coleta seletiva no campus da FUP. Observa-se que, de maneira geral, a maior dificuldade encontrada é a falta de motivação pessoal em colaborar $(43,0 \%)$, associado ao desconhecimento em realizar o descarte correto dos resíduos $(28,0 \%)$. No entanto, observou-se anteriormente (Figura 6 ), que a maioria dos respondentes $(82,5 \%)$ afirmou saber o que é a coleta seletiva, porém observa-se aqui que estes não sabem identificar a diferença 
entre o que é um resíduo orgânico e o que é um reciclável. Há também o relato de que faltam lixeiras para o correto descarte de resíduos.

Entre os grupos, exceto o de TAs, os demais apontaram que a maior dificuldade encontrada pela comunidade acadêmica é realmente a falta de vontade em colaborar com a coleta seletiva (Figura 11). Na GEAGRO e CNN, a falta de incentivo para a separação dos resíduos por parte da universidade é destaque e ocupa o segundo lugar. $\mathrm{Na}$ LEDOC esse motivo é similar àqueles que não sabem fazer o descarte de forma correta.

Problemas similares aos encontrados no presente artigo também foram relatados em outros estudos. Tangwanichagapong et al. (2017), em trabalho na Universidade da Tailândia, identificaram problemas no processo da coleta seletiva, como: dificuldade de acesso, número insuficiente de lixeiras, falta de clareza nas orientações nos rótulos das lixeiras, descarte incorreto dos resíduos nas lixeiras (o que desmotivava os demais usuários), além da falta de conscientização, gasto de tempo, e a diversidade de resíduos a serem separados.

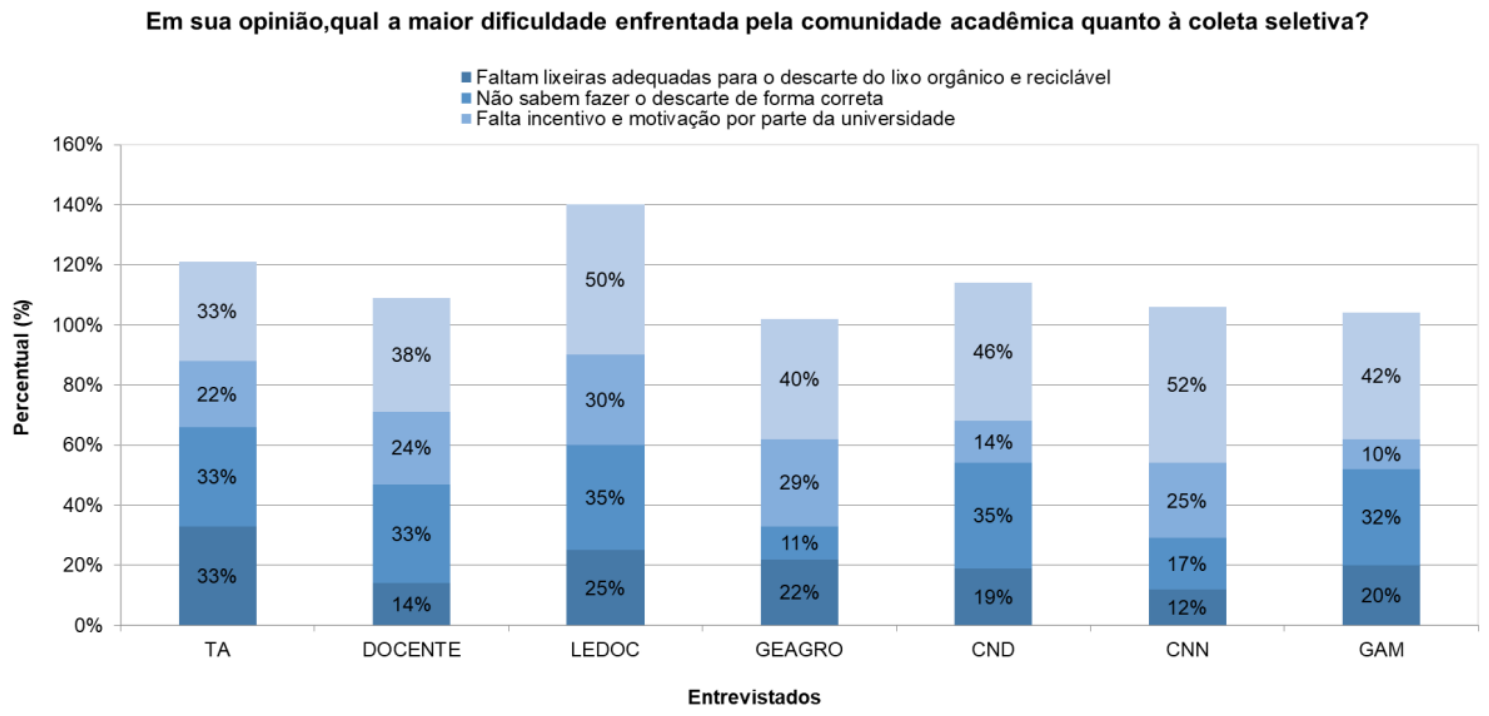

Figura 11: Entraves encontrados frente à coleta seletiva. Legenda: TA - Técnico Administrativo; LEDOC - Licenciatura em Educação do Campo; GEAGRO - Gestão do Agronegócio Diurno; CND - Ciências Naturais - Diurno; CNN - Ciências Naturais - Noturno; GAM - Gestão Ambiental - Noturno. Fonte: autoria própria.

Mtutu e Thondhlana (2016) realizaram uma pesquisa com funcionários e alunos da Faculdade de Educação da Universidade de Rhodes na África do Sul sobre energia e comportamento quanto à reciclagem de resíduos, e identificaram, entre as opiniões dos respondentes, que a falta de lixeiras, o acesso a elas, a falta de visibilidade e a educação sobre a reciclagem foram os principais pontos identificados como impedimentos na condução do processo. No referido estudo, $86,0 \%$ dos respondentes apontaram que a reciclagem não faz diferença, pois nem todos colaboram com a prática. Além disso, os 
respondentes afirmaram que têm desconfiança do sistema de coleta, ou seja, a separação na fonte é realizada, mas em alguma outra etapa do processo de gerenciamento os resíduos são misturados.

Resistência à mudança é uma ocorrência comum nas organizações e tem sido um grande obstáculo em muitos projetos de sustentabilidade (KOLLMUSS; AGYEMAN, 2002; VELAZQUEZ; MUNGUIA; SANCHEZ, 2005; OMRAN et al. 2009). Além disso, as pessoas geralmente se envolvem em ações pró-ambientais quando é fácil fazê-lo em termos de tempo e esforço (AMUTENYA; SHACKLETON; WHITTINGTON-JONES, 2009).

Em geral, tanto os docentes como os discentes, mesmo possuindo certo conhecimento sobre a coleta seletiva, estão desmotivados em relação à prática. Por outro lado, um estudo realizado no Instituto Asiático de Tecnologia na Tailândia por Mtutu e Thondhlana (2016) identificou que os funcionários dessa instituição são mais atuantes na coleta diferenciada dos resíduos do que os alunos. O sucesso de um programa de eficiência, conservação ou sustentabilidade de recursos depende muito do número de pessoas que participam desse programa, bem como da frequência e eficácia dessa participação (WOOLAM et al. 2003; DAVIS; O'CALLAGHAN; KNOX, 2008).

Os resultados do presente estudo vêm agregar informações do comportamento de uma comunidade acadêmica sobre questões ambientais. Sabe-se que liderar e coordenar iniciativas de gerenciamento de resíduos é difícil em organizações como universidades, que frequentemente são compostas por vários departamentos e divisões com muitos funcionários e estudantes. Zhang et al. (2011) citam que um meio de garantir a implementação eficaz de projetos como esse é nomear um indivíduo responsável por coordenar a gestão e o desempenho ambiental da instituição. No estudo realizado por Ukena et al. (2019) com universidades do sul da Nigéria, uma das indicações foi a criação de um currículo mais ecológico nas universidades, pois dessa forma preparam-se futuros profissionais e cidadãos com uma visão voltada ao desenvolvimento de ações sustentáveis.

Por fim, algumas lições estão sendo aprendidas com a implantação da coleta seletiva na FUP. É importante destacar que já existe conhecimento bastante razoável sobre a existência da coleta seletiva no campus. No entanto, os resultados indicam que outras ações de sensibilização precisam ser adotadas, como a realização de palestras educativas para toda a comunidade acadêmica, além da ampliação das atividades que já são realizadas. Muitas das barreiras para a execução da coleta seletiva pontuadas no presente estudo já foram previamente ressaltadas em outros estudos (VELAZQUEZ; MUNGUIA; SANCHEZ, 2005; AMUTENYA; SHACKLETON; WHITTINGTON-JONES, 2009; MTUTU; THONDHLANA, 2016). Cho (2019) recomenda que nos campi universitários as mensagens produzidas aumentem as motivações intrínsecas e extrínsecas dos alunos, como exemplo, dar a competência da reciclagem aos alunos e instituir ferramentas que permitam aos alunos avaliar o sucesso das suas ações. Esse autor ainda sugere a visualização das etapas de reciclagem

revista brasileira educação ambiental 
de forma a permitir que os alunos aprendam sobre aspectos positivos do seu comportamento em relação a reciclagem. O autor pontua ainda a utilização de campanhas com apelos emocionais pelo não envolvimento dos alunos nas ações de reciclagem, as quais também devem ser feitas, como desapontamento pela falta de participação do aluno no processo.

Sendo assim, algumas providências precisam ser tomadas para tratar as questões que restringem a participação das pessoas no processo da coleta seletiva: i) conscientizar os participantes das consequências ambientais das suas atitudes em não cooperar para o descarte seletivo dos resíduos; ii) ampliar o sistema de divulgação das informações sobre a coleta seletiva, garantindo que as informações sejam efetivamente compartilhadas entre alunos, professores e técnicos administrativos.

\section{Conclusões}

No fim do ano de 2019, o projeto de coleta seletiva da FUP completou quatro anos de atividade. Percebe-se que as ações realizadas têm contribuído na conscientização da comunidade acadêmica sobre o descarte seletivo dos resíduos. Considerando todos os grupos, mais de $80,0 \%$ dos entrevistados sabem do que se trata a coleta seletiva. No entanto, os discentes dos GEAGRO e da LEDOC são os menos informados quanto à existência da coleta seletiva no campus. Sendo assim, percebe-se que os discentes destes cursos precisam ser melhor abordados para que possam estar cientes do processo e de sua importância, e então cooperarem com o descarte seletivo dos resíduos. Ademais, os mais desmotivados para a prática são os discentes da LEDOC e $\mathrm{CNN}$, apesar de um grande percentual dos discentes deste último curso terem afirmado saber da existência da coleta seletiva na FUP. Uma das barreiras levantadas como impedimentos para as boas práticas de reciclagem foi a falta de motivação pessoal para a prática, além do desconhecimento sobre como fazer o descarte seletivo dos resíduos.

Dessa forma, para que o engajamento da comunidade acadêmica seja completo e haja mudança de comportamento dos indivíduos no sentido de serem participantes ativos do processo, voltados para a responsabilidade socioambiental, é fundamental que as ações educativas de sensibilização sejam contínuas e permanentes. Ademais, que essas ações sejam direcionadas para a motivação pessoal dos indivíduos que fazem parte do espaço acadêmico, além da institucionalização do projeto no campus, fatores estes, imprescindíveis para o sucesso do projeto.

\section{Agradecimentos}

Os autores agradecem ao Decanato de Extensão (DEX) da Universidade de Brasília, à prefeitura universitária, à direção da FUP, ao assistente da direção, Sr. Joaquim Oliveira, aos estudantes de extensão, bolsistas e voluntários que colaboraram nos projetos.

Revbea, São Paulo, V. 15, № 5: 124-141, 2020. 


\section{Referências}

ALSHUWAIKHAT, H.M. ABUBAKARB, I. An integrated approach to achieving campus sustainability: assessment of the current campus environmental management practices. Journal of Cleaner Production, v. 16, n. 16, 2008.

AMUTENYA, N.; SHACKLETON, C.M.; WHITTINGTON-JONES, K. Paper recycling pat-terns and potential interventions in the education sector: a case study of paper streams at Rhodes University, South Africa. Resources, Conservation and Recycling, v. 53, n. 5. 2009.

BRASIL. Lei n. 12.305, de 2 de agosto de 2010. Institui a Política Nacional de Resíduos Sólidos. Brasília, DF, 2010. Disponível em: $<$ http://www.planalto.gov.br/ccivil 03/ ato2007-2010/2010/lei//12305.htm>.

Acesso em: 15 dez. 2019.

BRASIL. Decreto n. 7.746, de 05 de junho de 2012. Regulamenta o art. 3o da Lei $n$ - 8.666, de 21 de junho de 1993, para estabelecer critérios e práticas para a promoção do desenvolvimento nacional sustentável nas contratações realizadas pela administração pública federal direta, autárquica e fundacional e pelas empresas estatais dependentes, e institui a Comissão Interministerial de Sustentabilidade na Administração Pública - CISAP. (Redação dada pelo Decreto no 9.178, de 2017). Brasília, DF, 2012. Disponível em: <http://www.planalto.gov.br/ccivil 03/ ato2011-2014/2012/decreto/d7746.htm>. Acesso em: 15 fev. 2020.

BRASII. Decreto n. 5.940, de 25 de outubro de 2006. Institui a separação dos resíduos recicláveis descartados pelos órgãos e entidades da administração pública. Brasília, DF, 2006. Disponível em: $<$ http://www.planalto.gov.br/ccivil 03/ Ato2004-

2006/2006/Decreto/D5940.htm>. Acesso em: 15 dez. 2019.

CÁRNIO, M.S. et al. Estímulos visuais e produção escrita de escolares com e sem queixas de alterações na escrita. Psicologia: Reflexão Crítica, v. 26, n. 3, 2012.

CHO, M. Campus sustainability: an integrated model of college student's, recycling behavior on campus. International Journal of Sustainability in Higher Education, v. 20, n. 6, 2019.

COUTO-JÚNIOR, A.F. Relatório campus UnB Planaltina. Universidade de Brasília, 2017.

DAVIS, G.; O'CALLAGHAN, F.; KNOX, K. Sustainable attitudes and behaviours amongst a sample of non-academic staff: a case study from Information Services Department, Griffith University, Brisbane. International Journal of Sustainability in Higher Education, v. 10, n. 2, 2008.

GIL, A.C. Métodos e Técnicas de Pesquisa Social. 6ª ed. São Paulo: Editora Atlas, 1995. 
GONÇALVES, M.S. et al. Gerenciamento de resíduos sólidos na Universidade Tecnológica Federal do Paraná Campus Francisco Beltrão. Revista Brasileira de Ciências Ambientais, n. 15, 2010.

GRØNHØJ, A.; THØGERSEN, J. Action speaks louder than words: the effect of personal attitudes and family norms on adolescents' pro-environmental behavior. Journal of Economic Psychology, v. 33, 2012.

KASSAYE, A.Y. Contemporary institutional solid waste management practices of Haramaya University, Eastern Ethiopia. African Journal of Science, Technology, Inovation and Development, v. 10, n. 2, 2018.

KOLLMUSS, A.; AGYEMAN, J. Mind the gap: why do people act environmentally and what are the barriers to pro-environmental behaviour? Environmental Education Research, v. 8, n. 3, 2002.

MTUTU, P.; THONDHLANA, G. Encouraging pro-environmental behavior: energy use and recycling at Rhodes University, South Africa. Habitat International, v. 53, 2016.

OMRAN, A. et al. Investigating households attitude toward recycling of solid waste in Malaysia: a case study. International Journal of Environmental Research, v. 3, n. 2, 2009.

PIKE, L. et al. Science education and sustainability initiatives - a campus recycling case study shows the importance of opportunity. International Journal of Sustainability in Higher Education, v. 4, n. 3, 2003.

RICHARDSON, G.R.A. Institutional motivations and barriers to the construction of green buildings on campus. International Journal of Sustainability in Higher Education, v. 8, n. 3, 2007.

ROBINSON, G.; READ, A. Recycling behaviour in a London Borough: results from large-scale household surveys. Resources Conservation \& Recycling, v. 45, 2005.

SAMUEL, P.R.S.; CAMPANI, D.B. A coleta seletiva dos resíduos sólidos na Universidade Federal do Rio Grande do Sul. In: Anais do 25 Congresso Brasileiro de Engenharia Sanitária e Ambiental, Recife, Pernambuco, Brasil, 2009

SIMA, M.; GRIGORESCU, I.; BĂLTEANU, D. An overwiew of campus greening initiatives at universities in Romania. International Journal of Sustainability in Higher Education, v. 20, n. 3, 2019.

TANGWANICHAGAPONG, $\mathrm{S}$. et al. Greening of a campus through waste management initiatives: Experience from a higher education institution in Thailand. International Journal of Sustainability in Higher Education, v. 18, n. 2, 2017.

UKENA, S.; NKAMNEBE, A.; IDOKO, E. Inhibitors of sustainable consumption: insights from university academic staff in southern Nigeria. Sustainable Development, v. 27, 2019.

Revbea, São Paulo, V. 15, № 5: 124-141, 2020. 
UNEP - United Nations Environmental Programme. IETC - International Environmental Technology Centre Urban Waste Management Strategy. Japan: Osaka/Shiga press. 2005. Disponível em: $<$ http://www.unep.or.jp/ietc/publications/spc/ewastema anualvol 2.pdf $>$. Acesso em: 01 dez. 2019.

UNEP - UNITED NATIONS ENVIRONMENTAL PROGRAMME. Report of the World Commission on Environment and Development: Our Common Future/Brundtland. 1987. Disponível em: <www.un-documents.net/ourcommon-future $>$. Acesso em: 28 nov. 2019.

UNEP - UNITED NATIONS ENVIRONMENTAL PROGRAMME. Agenda 21. $1992 . \quad$ Disponível em: $<$ https://sustainabledevelopment.un.org/content/documents/Agenda21.pdf>. Acesso em: 5 dez. 2019.

VELAZQUEZ, L.; MUNGUIA, N.; SANCHEZ, M. Deterring sustainability in higher education institutions. International Journal of Sustainability in Higher Education, v. 6, n. 3, 2005.

VENCATASAWMY, C.; ÖHMAN, M.; BRÄNNSTRÖM, T. A survey of recycling behaviour in households in Kiruna, Sweden. Waste Management and Research, v. 18, 2000.

WOOLAM, T.C.; EMERY, A.; GRIFFITHS, A.J.; WILLIAMS, K.P. A comparison of intended and claimed behaviour to actual in a new kerbside scheme, CIWM Scientific and Technical Review, v. 4, 2003.

YOSHIDA, S.E. 2016. 106f. Efetividade da coleta seletiva solidária para alunos de graduação da UTFPR - Londrina: aspectos ambientais e de sensibilização. Trabalho de Conclusão de Curso (Graduação) - Universidade Tecnológica Federal do Paraná. Disponível em: $<$ http://repositorio.roca.utfpr.edu.br/jspui/bitstream/1/6194/1/LD COEAM 2016 1 15.pdf >. Acesso em: 10 dez. 2019.

ZANETI, I.C.B.; SILVA, G.O. Projeto de Ação contínua: Coleta Seletiva Solidária/Núcleo da Sustentabilidade na Universidade de Brasília. Brasília, DF, 2016.

ZHANG, N. et al. Greening academia: developing sustainable waste management at Higher Education Institutions. Waste Management, v. 31, n. 7, 2011. 